\title{
1 The problem of axiological uncertainty
}

\subsection{Introduction}

We're uncertain about most things. And yet we constantly have to act. So uncertainty is the condition of almost any decision we make. Part of this uncertainty concerns purely descriptive questions. When ordering dinner at a restaurant we're uncertain what precisely we'll get. In starting a relationship we're not certain how it will end. And in fighting climate change we're uncertain about the effects of different measures. This raises the question about what you ought to do if you're uncertain about purely descriptive facts. But often, we're also uncertain about fundamental normative or evaluative questions. In response to climate change, say, we may be uncertain about whether we morally ought to be impartial in weighing different interests, or ought to give more weight to current than to future generations, to acquaintances than to strangers, or to human beings than to non-human animals. And this may not just be because we're uncertain about relevant empirical questions, such as what future generations, strangers or non-human animals desire. It might be, at least partly, because we're uncertain about the fundamental moral principles governing such decisions. So this raises the question about what you ought to do if you're uncertain about fundamental normative or evaluative facts.

This book is about this latter kind of uncertainty. More precisely, it's about a specific kind of such uncertainty: axiological uncertainty-i.e., uncertainty about fundamental axiological facts, or fundamental facts about moral value. My core question is how you ought to evaluate your options if you're uncertain about which axiology is true. Plausibly, there are fundamental moral facts beyond those of axiology-such as deontic facts about what you ought to do. And plausibly, there are fundamental normative or evaluative facts beyond those of morality-such as facts of prudence, rationality or aesthetics. So the question about how you ought to evaluate your options if you're axiologically uncertain is narrower than the general question about what you ought to do if you're uncertain about any fundamental normative or evaluative facts. For reasons that will emerge, this narrower question is simpler. And yet much can be learnt from it about the general problem too. So I'll focus on axiological uncertainty only. ${ }^{1}$

1 Most of the relevant literature focuses on the general problems of moral or normative uncertainty. For work on uncertainty concerning deontological morality specifically, see e. g. Tarsney (2018b); for work on uncertainty about the norms of decision theory, see e. g. MacAskill (2016b).

Ә Open Access. (c) 2021 Stefan Riedener, published by De Gruyter. (cc) BY-NC-ND This work is licensed under the Creative Commons Attribution-NonCommercial-NoDerivatives 4.0 International License.

https://doi.org/10.1515/9783110736199-001 


\section{The concept of 'm-value'}

Let me clarify my question. In one sense, there's a trivial answer to how you ought to evaluate your options if you're axiologically uncertain. You ought to do so in accordance with the axiology that is true. But that's not the answer I'm concerned with. To see that there might be a different one, consider

Purely descriptive uncertainty: Martha is suffering from a mild headache. Raphael has a pill he could give her, but he's uncertain about whether it's a pain reliever or a lethal form of poison. Actually, the pill is a pain reliever.

Is it better for Raphael to give his pill to Martha, or better not to? There's an extensive debate about such cases, mostly concerning the concept of 'ought': about whether there are two distinct senses of 'ought' ('subjective' and 'objective') or just a single one, about which one it would be, or which of the two is more basic or important. ${ }^{2}$ I won't go into the details of this debate. It seems undeniable that something has to be said, and can be said, in favour of both giving and not giving the pill. On the one hand, we can evaluate Raphael's options on the basis of their actual outcomes, without taking his uncertainty into account. We'll then say giving the pill is better. After all, Raphael will thereby relieve Martha's pain, and nothing else will happen. On the other hand, we can evaluate his options on the basis of the prospects they represent, taking his uncertainty into account. We'll then say not giving the pill is better. After all, Raphael will otherwise risk Martha's death for the sake of a headache. We may be interested in either of these judgments, and both uses of 'good' seem familiar. I'll remain neutral about which of them is more basic or important, or more in line with our common concept of goodness.

A parallel example can be given about axiological uncertainty:

Axiological uncertainty: Raphael has a pill, with which he can either relieve Martha of a mild headache or a donkey, Baldwin, of a much greater pain. He's uncertain between a speciesist and a non-speciesist axiology. According to the speciesist view it would be better to benefit Martha, and according to the non-speciesist view it would be better to benefit Baldwin. Actually, the speciesist view is right.

Here too, we can evaluate Raphael's options on the basis of their actual value, without taking his uncertainty into account. We'll then say it's better for him

2 See e. g. Hudson (1989), Jackson (1991), Howard-Synder (1997), Wiland (2005), Feldman (2006), Zimmerman (2008), Bykvist (2009b), Broome (2013, ch.3) or Kolodny and MacFarlane (ms), among many others. 
to benefit Martha. That's what (we're assuming) the true axiology says. However, we can again evaluate Raphael's options on the basis of the prospects they represent-now taking his axiological uncertainty into account. And if we do that, it's an open question which act is better, under his state of uncertainty. By benefiting Martha he risks effecting something comparatively bad. So intuitively, perhaps it's better for him to benefit Baldwin. Judgments of this kind may be less familiar from our ordinary practice, but they're no less distinct than in the purely descriptive case.

I'm concerned with judgments of this latter kind. To distinguish them conceptually, I'll use the term 'meta-value', or 'm-value' (or 'm-goodness'), to denote the goodness we refer to by taking into account both your descriptive and your axiological uncertainty. I'll use the simple term 'value' (or 'goodness') to denote the goodness we refer to by taking into account your purely descriptive, but not your axiological uncertainty. In the second example, I'll thus say it's better to benefit Martha, but (so far) an open question which of the two options is m-better for Raphael. And that's my core question: which of your options are m-better than which, if you're uncertain about which are better than which? This question has no trivial answer.

\section{The importance of the phenomenon}

It's worth reflecting briefly on how widespread axiological uncertainty is, how many of our decisions it affects, and how pressingly it does. Take questions of population ethics. Is a sufficiently large population of people with lives barely worth living better than a smaller population of people living wonderful lives? More basically, is it good to bring people into existence? And are the values of populations with different numbers of people even comparable? Philosophers have wildly contrasting views on these matters, and good arguments on all sides. ${ }^{3} \mathrm{We}$ shouldn't be certain of any answers. Yet these questions are crucial for very many decisions affecting the number and identity of future people. Those include the largest decisions of humanity-about global poverty, climate change, or (other)

3 See e. g. Huemer (2008) for an affirmative answer to the first question, Temkin (2012) or Parfit (1984) for a negative one; Broome (2004, ch.10) for objections to the intuition that bringing people into existence isn't positively good; Broome (2004, ch. 12) for the claim that there's only some vagueness in the comparisons, Bader (forthcoming) for an argument to the effect that such populations are thoroughly incomparable, and Parfit (ms) for a middle ground. More generally, see e. g. Arrhenius (forthcoming) for impossibility theorems, showing that a number of intuitively plausible principles of population ethics are incompatible. 
catastrophic risks like pandemics, artificial intelligence or nuclear wars. They include national policies of public health, security or migration. And they include very personal decisions-such as whether we use our resources to save other people's lives, thereby perhaps enabling them to have long chains of offsprings. ${ }^{4}$ In all of these cases, we must make choices under axiological uncertainty. And we must do so now. We can't wait until we're axiologically certain. Or more precisely, even to 'wait' and figure out answers would be a decision, and just raise the question whether that would be m-best. ${ }^{5}$ So, for very many decisions in the areas just mentioned, it seems vital that we reflect on how to evaluate options under axiological uncertainty.

But population ethics is just one example. Take the theory of welfare. Would it be good for us to experience pleasure artificially stimulated in our brains, have wonderful lives simulated in experience machines, or undergo enhancements through drugs or genetic engineering? Consider discounting. Does the wellbeing of future beings have the same value as that of currently existing ones, from our perspective, or should we discount wellbeing over time? Take environmental axiology. Does biodiversity, the intactness of ecosystems, or the flourishing of plants have value? Consider questions of equality. Is it intrinsically bad if people are unequally well off, through no fault of their own? Or consider animal welfare. Is it bad that non-human animals suffer in the wild, are being eaten by predators or die from starvation? Opinions on these matters diverge, each position has good arguments in its favour, ${ }^{6}$ and we can't be certain about them. Yet all of these questions are crucial for momentous decisions we face as humanity and individuals. And there's no way of postponing any decisions until we're certain about them.

Examples can be multiplied with ease. Decision-making under axiological uncertainty is unavoidably widespread. So it seems vital to have a theory of which options are m-better than which in light of such uncertainty. ${ }^{7}$

4 For the practical importance of population ethics, see particularly Broome (2004, ch.1) or Beckstead (2013, ch.1).

5 See MacAskill (2014, ch. 6) for a discussion of this question; also MacAskill et al. (2020a, ch. 9). 6 See e. g. Nozick (1974, 42 ff.) for a critical stance on pleasure simulations and the experience machine, $\mathrm{Ng}$ (1997, 1849 ff.) or Crisp (2006) for a positive one; Broome (2004, ch. 4) for arguments against discounting, and Beckstead (2013) or Bostrom (2003) for the radical implications of this; McShane (2017) for arguments and challenges for the idea that biodiversity has intrinsic value, Callicott (1989) for the view that ecosystems, and Taylor (1986) for the view that plants intrinsically deserve moral consideration; Cohen (1989) for a view on which equality matters, Parfit (1997) for a challenge; McMahan (2010) for the view that wild animal suffering matters.

7 For a further defence of this claim, see e. g. MacAskill et al. (2020a, ch. 1). 


\subsection{This book}

Let me outline what I'll do in this book. My goal is to defend a specific theory of axiological uncertainty-i. e., Expected Value Maximisation, or EVM. According to EVM, an option is $\mathrm{m}$-better than another if and only if it has the greater expected value-where the expected value of an option is a weighted sum of the values it's assigned by the axiologies, with weights representing the probabilities of these axiologies.

EVM extends the standard theory of decision-making under purely descriptive uncertainty to uncertainty about axiologies. So it's a promising view. But it raises two fundamental questions. The first is the question of meaning. It's the question about what EVM should even mean-or what it would be for an option to have a higher expected value than another. That's anything but clear. EVM features a number of concepts that have no use in ordinary language and are in need of explanation. One such concept is the quantitative notion of value. Whether an option has a higher expected value than another depends not just on ordinal intratheoretic value comparisons like

(A) according to axiology $T_{i}$, outcome $x$ is better than outcome $y$.

It depends on cardinal intratheoretic value comparisons, or facts of the form

(B) according to axiology $T_{i}$, the value-difference between outcomes $x$ and $y$ is $n$ times as great as the value-difference between outcomes $z$ and $t$.

To even understand EVM, we need to know what it is for such facts to hold. But unless more is said, we arguably don't. Suppose you claim that according to your favourite axiology, saving Edward's life is 3.7 times as good as saving Charlotte'sor that the value-difference between the status quo and Edward's death is 3.7 times as great as that between the status quo and Charlotte's death. Unless you explain what you mean by this, we don't understand your assertion. We might think you chose a swaggering way of expressing that according to your axiology, saving Edward is considerably better. But we'd think the same if your number was four, or 5.8. What is it for this factor to be 3.7? This isn't to say you can't explain what you mean. You may mean that saving ten people whose lives are exactly like Edward's would be equally good as saving thirty-seven whose lives are exactly like Charlotte's. And this may count as a proper explanation. The point is, you have to give some such explanation, or else your statement remains unclear.

But such intratheoretic comparisons are only one kind of fact that EVM presupposes, and that require explanation. Another, and even more problematic kind are facts about how value-differences compare across axiologies. And again, 
whether an option has a higher expected value than another depends not just on comparisons like

(C) the value-difference between outcomes $x$ and $y$, according to axiology $T_{i}$, is greater than the value-difference between outcomes $z$ and $t$, according to axiology $T_{j}$.

It depends on cardinal intertheoretic value comparisons, or facts of the form

(D) the value-difference between outcomes $x$ and $y$, according to axiology $T_{i}$, is $n$ times as great as the value-difference between outcomes $z$ and $t$, according to axiology $T_{j}$.

What it is for such comparisons to hold across axiologies is even less clear. Indeed, many people are sceptical that such comparisons can be meaningful. Edward Gracely says that intertheoretic comparisons are 'essentially meaningless' (1996, 330). James Hudson holds that there's generally no 'common measure' between different axiologies and that they therefore 'must be incomparable' (1989, 224; emphasis added). John Broome similarly contends that for most axiologies 'we cannot take a sensible average' between their different units of value (2012, 185). And many others are similarly sceptic. ${ }^{8}$

And there's a third problematic kind of fact. Whether an option has a higher expected value than another depends not just on qualitative probability facts like (E) axiology $T_{i}$ is very plausible.

It depends on quantitative probability facts, or facts of the form

(F) the probability of axiology $T_{i}$ is $p_{i}$,

for some $p_{i} \in[0,1]$. To understand EVM, we need to know what it is for such a fact to hold. And again, such statements have no use in ordinary language, and are in need of explanation. We understand what you mean in saying the speciesist axiology is implausible. But unless you say more, we don't understand what you mean in claiming it has a probability of 0.05 .

So it's anything but clear what it is for an option to have a higher expected value than another. But there's a second question. Even assuming we understand EVM, there's still the question of truth. It's the question about whether EVM is indeed the correct theory of m-value. For instance, even if we know what it would be for intertheoretic comparisons to hold, there's a question about whether any

8 See e. g. Gustafsson and Torpman (2014), Nissan-Rozen (2015) or Hedden (2016). 
of them do indeed hold. Perhaps as a matter of fact no intertheoretic comparison is true. So perhaps under axiological uncertainty, you simply ought to evaluate your options in accordance with the axiology that has the highest probability, as the 'My Favourite Theory'-approach suggests. ${ }^{9}$ Or perhaps intertheoretic comparisons hold, but you ought to adopt some less formal meta-deontological or meta-virtue-ethical principles under uncertainty. ${ }^{10}$ Or perhaps you ought to be risk-averse about moral value. There are plenty of reasonable alternative views. ${ }^{11}$ To endorse EVM, we need an argument to deny them-and preferably a systematic argument that goes beyond brute intuitions about cases.

In this book, I'll adopt an axiomatic approach from standard decision theory to answer the question of meaning and the question of truth about EVM. I'll introduce representation theorems for axiological uncertainty. In decision theory, representation theorems were devised for your preferences. They show that if your preferences satisfy certain axioms, they have an expected utility representation in terms of relevantly unique probability and utility functions. These theorems are conditional and purely mathematical results, implying the existence of certain functions under certain conditions. But they become philosophically significant if two assumptions are added. The first is a conceptual one: that if your preferences have an expected utility representation in terms of relevantly unique probability and utility functions, these functions can be taken to represent your credences and values-i. e., you can be interpreted as maximising the expectation of your values relative to your degrees of belief, rather than simply some mathematical measure. The second assumption is a normative one: that your preferences are normatively appropriate in some sense only if (or indeed if and only if) they satisfy these axioms. Together with these two assumptions, the formal theorems imply that your preferences are normatively appropriate only if (or if and only if) you maximise the expectation of your values, relative to your credences. ${ }^{12}$ And this is a philosophically significant claim.

9 See e. g. Gracely (1996) or Gustafsson and Torpman (2014).

10 See e. g. Guerrero (2007) or Williams (2011).

11 For still other views, see e. g. Barry and Tomlin (2016), or (concerning merely ordinal and noncomparable theories) MacAskill (2016a), Tarsney (2019a) or MacAskill et al. (2020a). For a helpful recent survey of the debate, see e. g. Bykvist (2017); also MacAskill et al. (2020a).

12 The biconditional will be true if the second additional assumption is put in terms of a biconditional. That's because the result of the representation theorems, and the first additional assumption, could also be stated as biconditionals: if your preferences have an expected utility representation, they also satisfy the axioms; and if you maximise the expectation of your values relative to your degrees of belief, then your preferences also have an expected utility representation. The three claims, stated as biconditionals, imply that your preferences are normatively appropriate if and only if you maximise the expectation of your values, relative to your credences. Since the two 
I'll devise a similar argument for EVM in the context of axiological uncertainty. But instead of your preferences, our theorems will concern the facts about which options are m-better than which, relative to your state of uncertainty. So as I'll understand it, a pertinent representation theorem in our context shows that if these $m$-value facts satisfy certain axioms, they have an expected utility representation in terms of relevantly unique probability and utility functions. I'll provide such theorems, and add two similar assumptions. I'll add the conceptual assumption that if the $\mathrm{m}$-value facts have such a representation, the relevant functions can be taken to represent the probabilities and value functions of our axiologies. And I'll add the normative or meta-axiological assumption that (at least for an interestingly large set of underlying axiologies) the m-value facts do indeed satisfy these axioms. Given these two assumptions (and at least for the axiologies under consideration), the theorems imply EVM.

In other words, I'll argue that these representation theorems ground compelling answers to our two questions. First and foremost, they afford us a clear explication of what EVM means. In light of them, we can understand cardinal intertheoretic comparisons, top-down, in terms of $m$-value facts. For axiologies to compare in a certain way would just be for some such facts to hold. And something equivalent is true for cardinal intratheoretic comparisons and quantitative probability facts. Moreover, once we explicate comparisons and probabilities in this manner, the theorems provide a systematic argument to the effect that EVM is true. If the m-value facts satisfy the relevant conditions, EVM simply follows. Every other view-My Favourite Theory, or meta-deontological principles, or forms of risk-aversion-must be false. So the axiomatic approach can compellingly explicate and vindicate EVM. Or at any rate, it can do so for an interestingly large set of underlying axiologies. Our axioms aren't trivial. There are certain axiologies for which they don't hold. And we arguably can't be certain that these axiologies are false. So the axiomatic approach can't ground EVM as a fully general theory of axiological uncertainty. It can ground EVM, at most, as a theory about a certain range of axiologies. But I'll suggest that this range is interestingly large, and that our result thus remains highly significant.

This extension of standard decision theory to the case of axiological uncertainty raises a number of new issues. First, the theorems raise novel formal questions. Axiological uncertainty is structurally different from purely descriptive uncertainty, as commonly understood. Under axiological uncertainty, the propositions you're uncertain about don't determine the outcomes your choices result in.

conditionals just mentioned are rather trivial, for simplicity, I'll henceforth state the argument in the form in which I've stated it in the main text. 
They determine the utilities or values of these outcomes. This adds complexity. In particular, it raises questions about how to separate probabilities and valuesor cases where an axiology has a low probability but an inflated value function from cases where it has a high probability but a deflated value function. Also, in decision theory the standard assumption is that there are only coherence constraints on your preferences, such as the von Neumann-Morgenstern axioms. Under axiological uncertainty, there are arguably further constraints on the m-value facts, on how they relate to the underlying axiologies. So this raises a question about what these constraints plausibly are. All of this requires novel technical machinery. Second, the two extra assumptions raise novel philosophical questions. The meta-axiological assumption raises the question whether the axioms are plausible constraints on m-value-e.g., in light of the problem of intertheoretic comparisons-and on the underlying axiologies, or on moral theories generally. And the conceptual assumption raises the question whether we can interpret the relevant functions as denoting actual axiological probabilities and values. So if I'm right, the results not only compellingly ground a theory of axiological uncertainty, but also provide a cogent substantive extension of decision theory.

In short, EVM raises the questions of meaning and truth. Both require substantive arguments to be resolved. Representation theorems promise to ground such arguments. But it requires novel technical and philosophical work to provide and apply such theorems. This work is the object of this book. Let me spell out in more detail how it will proceed. After this introductory chapter, the book will feature five main chapters, plus an appendix. In the remainder of the present chapter, I'll answer objections against the importance of m-value, and thus clarify why our inquiry is important. In Chapter 2, I'll state the most basic theorem of this book, and the assumptions needed to turn this into a vindication of EVM. This will introduce the argument of the axiomatic approach in its simplest form. In Chapter 3, I'll discuss whether this argument is convincing. I highlight three potential problems for it, specific to the context of axiological uncertainty: the problem of intertheoretic comparisons, the meaning of axiological probabilities, and the existence of incommensurabilities in value.

The remaining three chapters address these problems in turn. In Chapter 4, I'll discuss the problem of intertheoretic comparisons. I argue that existing proposals of such comparisons are unsatisfactory. I provide an argument for why at least some such comparisons must nonetheless hold. And I then introduce a constructivist explanation of why they do, and suggest this account can ground our overall argument. In Chapter 5, I'll focus on the notion of a probability distribution over axiologies. I introduce a more complex representation theorem, which provides a formal separation of credences and values. I then argue against various strands 
of recent scepticism about such theorems, and suggest they provide the best account of probabilities, at least in our context. This has important implications for the normative structure of EVM. In Chapter 6, I'll relax the least plausible substantive condition of our theorem-the Completeness axiom. I state a representation theorem without this axiom, which allows our theory to cover axiologies that feature intra- or intertheoretic incommensurabilities, and grounds the most comprehensive argument of the book. I end the chapter with a discussion of whether the approach can be extended beyond axiological to moral uncertainty generally, and raise concerns about this extension.

As this indicates, there's a range of issues related to axiological uncertainty that I won't address in this book. Let me flag three of them, just to set them aside. First, I won't address any questions of applied axiological uncertainty: the implications of EVM for population ethics, future discounting, the welfare of nonhuman animals, or whatever. My discussion remains purely abstract and general. ${ }^{13}$ Second, I won't say much more about the normative import of m-value. In particular, I won't discuss the existence of a form of overall-(meta-)goodness. Suppose your best option is $a$, and your m-best option is $b$. And suppose you're also uncertain about theories of axiological uncertainty, and that according to the true theory of uncertainty about m-value, your $\mathrm{m}^{2}$-best option (as we might call it) is $c$. There's a question about whether some option is overall-best, besides being best, $\mathrm{m}$-best, or $\mathrm{m}^{2}$-best. I think there's no such form of goodness. But I won't enter this debate here. ${ }^{14}$ Relatedly, I won't discuss the deontic status of your m-best option. There's a question about whether there are any deontic meta-norms, and if there are, about what they say, and whether they're norms of morality, rationality, or some other source of requirements. I think there's at least a requirement of rationality to the effect that you ought, if one of your options is m-best, ceteris paribus choose it. ${ }^{15}$ But nothing hinges on this here. ${ }^{16}$ I'll just present a theory of m-value. Third, I'll largely set aside metaethical issues underlying the problem of normative uncertainty. My framework presupposes some notion of axiological 'truth', and a notion of an agent's 'credences' in an axiology. There's a question about whether the problem arises, or can be made sense of, within non-cognitivist or

13 For implications of normative uncertainty for practical ethics, see e. g. Pfeiffer (1985), Oddie (1994), Guerrero (2007), Moller (2011), Williams (2011), Broome (2012, 183 ff.), Bykvist (2013), Greaves and Ord (2017), Barry and Tomlin (2019), MacAskill (2019), Tarsney (2019b), Koplin and Wilkinson (2019) or MacAskill et al. (2020a, ch. 8).

14 See Sepielli (2013b, 13 ff.) for a defence of a related view.

15 In other words, I think there's a wide-scope requirement of rationality. See e. g. Broome (2013, ch. 7) for the distinction between 'wide-' and 'narrow-scope' requirements.

16 For a helpful survey and discussion of such questions, see Bykvist (2017). 
anti-realist views. Some people think non-cognitivists cannot account for the phenomenon of normative uncertainty; ${ }^{17}$ others think they can. ${ }^{18}$ But in any case, the ability to make sense of normative or evaluative uncertainty is generally treated as a desideratum on metaethical views. If such a view cannot account for such uncertainty, that's standardly seen as a problem for this view, rather than for the project of devising a theory of normative or evaluative uncertainty. ${ }^{19}$ I think this is a plausible view of the dialectic. So I'll set general metaethical questions aside. ${ }^{20}$

\subsection{Objections}

One might think that even if we're uncertain about many axiological questions relevant to many of our decisions, we don't need a theory of m-value. So before I defend such a theory, let me address the three most prominent objections to the importance of that enterprise. This will clarify why it matters.

\section{Fetishism}

Some people have argued that we don't need a theory of m-value (or of moral uncertainty more generally) because concern with $\mathrm{m}$-value is fetishistic. Suppose you have a choice between a vegan meal and a steak, and are uncertain between a speciesist and a non-speciesist axiology. You find it more plausible that the speciesist view is right, and that it's better to choose the steak. However, you believe that if the non-speciesist view is right, killing non-human animals is terrible, and that it's thus m-better to turn vegan. So you do that, because you think it is mbetter. Then your vegan diet doesn't spring from a genuine concern for non-human animals, it seems. Rather, you seem to care about m-value as such-about whatever turns out to be m-valuable, simply because it's m-valuable. And as Michael Smith pointed out in a similar context, that might seem inappropriate:

17 See e. g. Smith (2002), Bykvist and Olson (2009), Bykvist and Olson (2012), Bykvist and Olson (2017) or Björkholm et al. (forthcoming).

18 See e. g. Sepielli (2012), Eriksson and Francén Olinder (2016), Beddor (2020) or Ridge (2020). 19 See e. g. Smith (2002).

20 I'll defend constructivism about intertheoretic comparisons in Chapter 4. But most of my arguments in the other chapters don't hinge on this. And constructivism about intertheoretic comparisons doesn't imply constructivism about axiology or morality more generally. So I'm not committed to any general metaethical view. 
Good people care non-derivatively about honesty, the weal and woe of their children and friends, the well-being of their fellows, people getting what they deserve, justice, equality, and the like, not just one thing: doing what they believe to be right, where this is read de dicto and not de re. Indeed, commonsense tells us that being so motivated is a fetish or moral vice. $(1994,75)$

Similar considerations arise for $\mathrm{m}$-value. Concern with $\mathrm{m}$-value might seem inappropriately fetishistic. Brian Weatherson, among others, concluded for this reason (concerning the case just described) that 'it would be perverse for [you] to turn down the steak', or more generally, that 'a mere probability that meat eating is immoral should not change one's actions, or one's evaluations of meat eaters' $(2014,2){ }^{21}$

It's not entirely clear what the inappropriateness of being motivated by $\mathrm{m}$ value should consist in. I see three interpretations of this fetishism-worry. On the first interpretation, the inappropriateness of being motivated by $\mathrm{m}$-value is a matter of first-order value. It's better to help non-human animals, say, out of unmediated concern with their wellbeing rather than out of a belief that it's m-best. According to the true axiology, concern with $\mathrm{m}$-value is comparatively bad. If this is the idea, I don't deny it. It's a first-order axiological claim, and nothing I say contradicts it. In fact, it can be accommodated in the theory I outline. If an action can be done with different motives, we can treat these motives as different options, on a par with doing something altogether different. So if being motivated by $\mathrm{m}$-value is bad, EVM will imply it's comparatively $\mathrm{m}$-bad. This is perfectly consistent. What I'll defend is a criterion of m-betterness, not a decision procedure, or an account of how to make decisions in practice. ${ }^{22}$ So it may well be comparatively $\mathrm{m}$-bad to consciously act on considerations of m-value. Now of course, if it's plausible that de dicto concern with $\mathrm{m}$-value is terrible, EVM might become self-effacing. ${ }^{23}$ It might imply we should never consciously act on it, or indeed should forget it altogether in practice. And although that would still be consistent, it might raise the question why we should spend much time thinking about it. But it doesn't seem plausible that such concern with $\mathrm{m}$-value is so bad as to dominate all other possible badness. And in any case, to find out whether it does, or how it weighs against other forms of disvalue under uncertainty, we need a theory of m-value. So if the inappropriateness is understood as a first-order claim about value, it doesn't establish that we don't need a theory of axiological uncertainty.

21 The fetishism objection is also raised in Hedden (2016).

22 For the classic distinction between a criterion of rightness and a decision procedure in utilitarianism, see e. g. Bales (1971), Mill (1861, ch. 2, par.19) or Sidgwick (1907, 413).

23 For the notion and problem of 'self-effacingness', see Parfit (1984, ch.1). 
On a second interpretation, this inappropriateness takes a different form. In the above quote, Smith says that 'good people' are motivated by what's valuable de re. Perhaps this doesn't mean that de dicto motivation is bad. It might just mean that we aren't ideal moral agents if we're guided by m-value. Moral philosophy doesn't need a theory of m-value because ideal agents aren't motivated by such value. And again, perhaps this is true. Perhaps an ideal agent is motivated de re by what's valuable. But the entire project of normative uncertainty is based on the fact that we aren't ideal agents. We're inescapably uncertain about what's valuable; and our project is to determine how we fallen creatures should evaluate our options. The question about what ideal versions of ourselves would do is simply different from the one we're addressing. And it can't show that we don't need a theory of m-value. For all that this second interpretation says, given our human limitations, it still seems m-value is important for us.

Here's a third interpretation. Perhaps the objection is not just that ideal agents aren't motivated by m-value. Perhaps the objection is that even non-ideal agents shouldn't be. Understood thus, the objection isn't that we don't need any theory of what to do under normative uncertainty. Instead, it advocates a specific such theory, according to which under uncertainty we should always intuitively follow something we care about de re. This claim addresses the question of this book, and contradicts the theory I outline. But it doesn't seem very plausible. To begin with, this theory will often fail to guide us. If we're axiologically uncertain, there will often not be anything we unqualifiedly care about de re. We'll be torn between different values, both doxastically and emotionally. In such cases, the present theory won't tell us what to do. But more importantly, when it does offer guidance, this guidance often seems rather dubious. As I indicated, we have to make enormously important decisions under uncertainty-about climate change, artificial intelligence, global poverty, and so on. Making a bad decision concerning any of these issues might have enormous ramifications, involving vast numbers of beings until some very far future. It seems very implausible that we should run the risk of incurring such astronomical badness, just to avoid a particular motive.

I can't think of any other plausible interpretation of the fetishism worry. So as far as I see, although being motivated de re by the good may in some ways be preferable to being motivated de dicto by m-value, this doesn't imply that we don't need a theory of the latter. ${ }^{24}$

24 For other responses to the fetishism objection, see Sepielli (2016), Aboodi (2017), Hicks (2019) or MacAskill et al. (2020a, ch. 2). 


\section{Blamelessness}

Here's another objection against the importance of m-value, due to Elizabeth Harman (2015). ${ }^{25}$ Harman claims that your moral uncertainty is irrelevant for what you subjectively ought to do. In a nutshell, her argument is this:

(G) Suppose your moral uncertainty was relevant to what you subjectively ought to do. Then, if you were certain of a false moral theory and acted in accordance with it, you wouldn't be blameworthy.

(H) However, if you're certain of a false moral theory and act in accordance with it (and objectively morally wrongly), you are blameworthy.

(I) Therefore, your moral uncertainty is irrelevant to what you subjectively ought to do.

Why should we believe these premises? Harman thinks premise $(G)$ follows from a very general fact about blameworthiness and subjective obligation-viz., that

(J) an agent is blameworthy for her behaviour only if she acted as she subjectively ought not have acted. $(2015,56)$

Being certain of false moral theory is just a limiting case of being morally uncertain. So given (J), if moral uncertainty was relevant to what you subjectively ought to do, such false certainty would exculpate. To illustrate premise (H), Harman considers a Mafia family member, who's certain they're obliged to kill innocents when necessary for the interests of the family. Harman claims that they're blameworthy if they kill innocents on the basis of their belief. That's because

(K) a person is blameworthy for her wrongful behaviour just in case it resulted from her failure to care de re about what is morally important-that is, from her failure to care adequately about the non-moral features of the world that in fact matter morally. $(2015,67)$

Clearly, our mafia member doesn't care adequately about the lives of innocents. So they're blameworthy, quite regardless of their beliefs.

However, both of these premises seem dubious. Start with the second. According to $(\mathrm{H})$ and Harman's view of blameworthiness, it's irrelevant how you acquired your false moral beliefs, and how difficult it would have been for you to have correct ones. You're culpable whenever you do something objectively wrong, on the basis of false moral beliefs or concerns. There's a large literature on responsibility,

25 Hedden (2016) tentatively raises the same objection. 
and this isn't the place to discuss it. ${ }^{26}$ But suffice it to note that, intuitively, this seems very implausible. It can be extremely difficult for us to have correct moral beliefs. That's in part because we're thoroughly social. It's highly dependent on the society we live in not only which moral arguments and views we encounter, but also what intuitions we have. If everyone around us is convinced of a falsity, it can arguably require outstanding sensitivity to access the truth. So we can end up with wrong beliefs even when, intuitively, we've done all that's required by way of epistemic caution. And in such cases we intuitively aren't blameworthy for our beliefs, or for acting upon them. I take it this can be true even for the conviction that honour can require the killing of innocents. ${ }^{27}$ But it seems clearly true for beliefs about more nuanced moral matters like those outlined above-population axiology, the theory of welfare, or future discounting. It seems bizarre to suggest that, regardless of the sincerity and care you devote to your moral inquiry about these difficult questions, you're blameworthy if you end up in the wrong. Whatever the correct theory of responsibility, Harman's uncompromising view of blameworthiness seems false. $(\mathrm{H})$ is wrong.

That's enough to block her argument. But we can also reject premise (G). Harman doesn't argue for her supporting assumption (J). In fact, if I understand her correctly, she simply identifies the relevant subjective 'ought' as the 'ought' for which this assumption holds. So (J) isn't a substantive claim about the subjective 'ought'. It's simply a suggestion about why we should be interested in such an 'ought' in the first place. We're interested in the 'subjective ought' insofar as it's the ought that determines blameworthiness. But that's dubious. Suppose arguendo that her view of blameworthiness was right, and that your blameworthiness was fully determined by your non-moral beliefs. Then consider your first-person perspective. If you're morally uncertain, it's singularly unhelpful for you to know you avoid being blameworthy only if you act in accordance with the true moral view. You don't know what that is. So even insofar as you care about blameworthiness, you still face a question-about whether it's reasonable to prefer a low risk of being very blameworthy to a large risk of being only mildly to blame. The answer will pick out a subjective 'ought'. And even if this 'ought' doesn't determine blameworthiness, it's important from your perspective. But more fundamentally, your motivation arguably shouldn't be to avoid blameworthiness in the first place. It should quite simply be to do or try to do good (or do the right or the virtuous). And so you

26 See particularly Rosen (2003; 2004) or FitzPatrick (2017) for criticism of (H) and (K). For a collection of essays on the epistemic condition for moral responsibility, see Robichaud and Wieland (2017).

27 For a vivid description of a culture with such a code, and of the difficulty of rejecting it if you're born into such a culture, see e. g. Thesiger (2008). 
face a more fundamental question-about whether it's reasonable to prefer a low risk of doing something very bad to a large risk of doing something slightly bad. Insofar as you care about doing good, and quite regardless of blame, m-value is important for you. So it's false that we're interested in such an ought just because it determines blameworthiness. At least from the perspective of agents, rather than third-party blamers, it would remain important even if it didn't. By the same token, it's false that the connection between moral uncertainty and blameworthiness expressed in $(\mathrm{G})$ holds. Moral uncertainty would be relevant to the subjective ought even if it didn't determine blameworthiness.

In sum, Harman's view of blameworthiness seems false. And even if true, it can't establish the 'irrelevance of moral [or axiological] uncertainty' $(2015,53)$. From the first-person perspective, the importance of m-value doesn't hinge on questions of praise and blame at all. ${ }^{28}$

\section{Regress}

Here's a third worry. Suppose we say we need a theory of m-value because we aren't in a position to know the true axiology, and thus first-order axiologies aren't action-guiding for us. ${ }^{29}$ This claim seems to run into a regress. Just as we're not in a position to know the true theory of value, we're arguably not in a position to know the true theory of m-value. So if axiologies aren't action-guiding, due to our uncertainty, then theories of m-value won't be action-guiding either. So why should we be interested in m-value (or any $m^{n}$-value) in the first place?

There's an answer to this worry, even if indeed we aren't in a position to know the true theory of m-value. ${ }^{30}$ Note first that, in a standard sense of that term, we can be 'guided' by norms even if we aren't certain about them. Consider the norm that it's best to get 0.8 grams of protein per day and kilogram of body weight. Presumably, we can't be entirely certain about that norm. The best amount of protein might well be 0.7 or 0.9 grams. But the norm seems perfectly action-guiding, in any standard sense of that term. It's not that, without some extra algorithm about how to deal with our uncertainty, we'd be utterly paralysed, or that any deliberate protein consumption would be a random stab in the dark. Presumably, if we act in the face of such uncertainty without explicitly considering meta-norms about doing so, we act on an implicit acceptance of some such higher-order norms. Or

28 For other discussions of Harman's worry, see Sepielli (2018) or Geyer (2018).

29 See e. g. Hudson (1989).

30 The main idea behind this answer was sketched in Sepielli (2014). 
more precisely, we act on the basis of intuitions about what to do in the face of our uncertainty. We can do that. We have such intuitions, it seems. So similarly, even if we're axiologically uncertain, we needn't be totally dumbstruck by this unless we have a theory of m-value. Our axiologies can still guide us in some sense.

Why then do we need to reflect about m-value? The reason isn't to overcome paralysis or absolute crapshoots. Instead, it's simply to make better decisions in light of uncertainty. Reflecting about $m$-value is a form of gathering evidence about what to do in the face of our uncertainty. And it's, quite simply, almost always better to act on the basis of more evidence.

Or at any rate, that seems plausible. It would take some argument to establish it firmly. In his classic paper 'On the Principle of Total Evidence' (1967) Irving John Good showed that it's always better to act on more evidence. More precisely, he proved that the expected value of the action that has the highest expected value after taking into account more evidence is always greater than that of the action with the highest expected value before we take this evidence into account-if the cost of taking it into account is neglected, and unless the action with the highest expected value would be the same for whatever piece of evidence we gather. So if reflection on $\mathrm{m}$-value is like gathering evidence, then the expected value of acting after reflection about m-value will be greater than that of acting without that reflection, if the cost of the reflection is neglected and unless the action with the highest expected value would be the same for all pieces of evidence. Now our argument can't be so straightforward. Good assumed that whatever evidence we receive, we'll do what maximises expected value, given that evidence. But if we receive good evidence for a theory of $\mathrm{m}$-value that says we shouldn't maximise expected value, this assumption is dubious. Moreover, one would clearly have to characterise formally what acting 'without further reflection' would amount to. One would have to argue more fully for the parallel between evidence-gathering and moral reflection. One would ultimately have to take into account the cost of moral reflection too, and thus say something about the efficacy of moral reasoning. And of course, we would also have to argue that EVM is the correct theory of $\mathrm{m}^{2}$-value. It would take some argument to establish this firmly. But it does seem very plausible that acting after serious reflection about $m$-value will be $m^{2}$-better than acting unreflectedly-just like it seems plausible that acting after reflection about value will be m-better than acting unreflectedly. ${ }^{31}$

Now there's a next worry that the objector might raise. To show that reflecting about $\mathrm{m}$-value is good, we have to assume some form of EVM about $m^{2}$-value-or perhaps some other normative theory with the same implication. The proponent

31 This last claim is defended in MacAskill (2014, ch. 7). 
of the regress objection might claim that we're begging the question against her: that we aren't entitled to assume EVM, or any other theory, but instead would have to take into account uncertainty about that again, and so on. In other words, she might demand that we show not only that reflection about $\mathrm{m}$-value will plausibly be $m^{2}$-better, but also that it's $m^{3}$-better, and perhaps $m^{n}$-better all the way up. But note what the objector is now demanding. She's in effect asking us to prove beyond any doubt that our project is ex ante worth pursuing. I don't see how we could do that. But it seems an unreasonable demand. It would question not only why we should reflect about what's m-valuable, but also why we should reflect about what's valuable-or indeed why we should reflect on anything, or do anything else that seems prima facie worthwhile. It's a most radical normative scepticism. This may be an interesting philosophical problem. But it's not a problem I can address in this book, and not one I need to answer before moving forward.

So the main motivation for reflection on m-value isn't that we'll always be in a position to know what's m-best, or can't be guided in any ways by norms we're not certain about. It's that it's plausibly ex ante better to reflect about m-value and act on that reflection rather than to act in the face of uncertainty without any further reflection. Or at any rate, that's the assumption on which I'll proceed. ${ }^{32}$

32 For other illuminating discussions of (related) regress-problems, see e. g. Sepielli (2013b), Trammell (forthcoming) or Tarsney (ms). For an argument that objective norms aren't actionguiding, see Fox (2019); for a challenge to this, see Barnett (forthcoming). 